\title{
Advance Directives in Home Health and Hospice Agencies: United States, 2007
}

\author{
Resnick, Helaine E. PhD, MPH ${ }^{1,2}$; Hickman, Susan E. PhD³; Foster, Gregory L. MA, MPH ${ }^{1}$ \\ ${ }^{1}$ American Association of Homes and Services for the Aging, Washington, DC, USA \\ ${ }^{2}$ Department of Medicine, Georgetown University, Washington, DC, USA \\ ${ }^{3}$ School of Nursing, Indiana University, Indianapolis, IN, USA
}

\section{Corresponding Author:}

Helaine E. Resnick, American Association of Homes and Services for the Aging, Georgetown University, 2519 Connecticut Avenue, NW Washington, DC 20008, USA Email: hresnick@aahsa.org

\begin{abstract}
This report provides nationally representative data on policies, storage, and implementation of advance directives (ADs) in home health and hospice $(\mathrm{HHH})$ agencies in the United States using the National Home and Hospice Care Survey. Federally mandated ADs policies were followed in $>93 \%$ of all agencies. Nearly all agencies stored ADs in a file at the agency, but only half stored them at the patient's residence. Nearly all agencies informed staff about the AD, but only $77 \%$ and $72 \%$ of home health agencies informed the attending physician and next-of-kin, respectively. Home health and hospice agencies are nearly universally compliant with ADs policies that are required in order to receive Medicare and Medicaid payments, but have much lower rates of adoption of ADs policies beyond federally mandated minimums.
\end{abstract}

This is the author's manuscript of the article published in final edited form as:

Resnick, H. E., Hickman, S. E., \& Foster, G. L. (2011). Advance directives in home health and hospice agencies: United States, 2007. The American Journal of Hospice \& Palliative Care, 28(7), 467-474. http://doi.org/10.1177/1049909111399751 


\section{Introduction}

Most older adults prefer to age in place 1,2 and spend the last days of their lives in their own homes.36 There are numerous benefits associated with older adults' ability to remain in the community at the end of life including lower rates of hospitalization, 7 and the ability of family caregivers and friends to collaborate with patients and formal care providers in care decisions and care giving.8,9

Home and community-based services (HCBSs) are essential to enable seniors to age in place in diverse residential settings before and after acute health events.10-12 Home and community-based services are often provided in situations where issues including maintenance of dignity and independence, control over treatment options, and achieving a sense of closure at the end of life are commonly encountered.13-17 Home health and hospice $(\mathrm{HHH})$ services are critical elements of the HCBS stream,18 and the number of $\mathrm{HHH}$ agencies and patients has increased substantially in the past 15 years. In 1992, there were approximately $8000 \mathrm{HHH}$ agencies in the United States with 1.45 million current home heath patients and annualized hospice discharges. By 2007, the number of agencies had nearly doubled to 14500 , with 2.5 million current home health patients and annualized hospice discharges.19-21 Ensuring patient autonomy is an important consideration in the provision of HCBS.

The intent of the Patient Self-Determination Act (PSDA)22 is to provide an opportunity for adults to express their preferences for medical treatment and to educate patients on advance directives (ADs), with the overall goal of assisting patients in effecting a degree of autonomy over the circumstances of their care. Under the PSDA, an AD is defined as a written instruction, such as a living will, health care proxy, or durable power of attorney over health care to facilitate treatment when the patient is incapacitated. Certified HCBS providers must comply with specific features of the PSDA, including: (1) providing all adults with written information about their rights under state law to make decisions about 
their medical care, accept or refuse medical or surgical treatment, and formulate, at the individual's option, an AD; (2) inform patients about the agency's written policies on implementing ADs; (3) document in the patient's medical record whether he or she has executed an AD; (4) not condition the provision of care or otherwise discriminate against an individual based on whether he or she has executed an AD; and (5) provide staff and community education on issues concerning ADs.

The execution of $A D s$ is one form of advance care planning (ACP) - a term used to describe processes involved in learning about options for end-of-life care before a health crisis occurs. Recent evidence indicates that seniors who engage in ACP tended to receive care that was associated with their preferences 23 and that the surviving members of these families experienced less stress, anxiety, and depression.24 Given the marked growth in HCBS and the fact that it has been 20 years since passage of the PSDA, it is interesting to note that there are limited data describing the specifics of how $\mathrm{HHH}$ agencies implement ADs with their patients, patient families, or staff, or whether agencies go beyond federally mandated activities in their approach to ADs. This report addresses the gap in the literature by providing nationally representative, benchmark data on policies, storage, and implementation of ADs in $\mathrm{HHH}$ agencies in the United States.

Methods

Study Design and Data Collection

The 2007 National Home and Hospice Care Survey (NHHCS) was designed to provide descriptive information on $\mathrm{HHH}$ agencies, their staffs, services, and patients.25 The NHHCS used a stratified 2stage probability sample design. The first stage, carried out by the Centers for Disease Control and Prevention's National Center for Health Statistics (NCHS), was the selection of HHH agencies representing the universe of agencies providing $\mathrm{HHH}$ services in the United States. The sampling frame 
was constructed using 3 sources: (1) The Centers for Medicare \& Medicaid Services Provider of Services file of home health agencies and hospices, (2) State licensing lists of home health agencies compiled by a private organization, and (3) The National Hospice and Palliative Care Organization file of hospices. The combined files were matched and identified duplicates were removed, resulting in a sampling frame of 15488 agencies. Of the 1545 agencies selected for the sample, 1461 (95\%) were considered "in scope" and appropriate for the sample. The 84 "out-of-scope" agencies were ineligible for one or more of the following reasons: did not meet the definition used in the survey, had gone out of business, was a duplicate of another sampled agency, or had merged with other sampled agencies. Of the in-scope agencies, 1036 (71\%) agreed to participate. The NHHCS was administered in sampled HHH agencies between August 2007 and February 2008.26,27

\section{Ascertainment of Information on ADs}

Agency practices related to policies, storage, and implementation of ADs were ascertained in the Agency Qualifications and Characteristics module of the survey.28 This module was administered in person to the agency director by a trained interviewer. The survey questions and response options were as follows: (1) "Does this agency follow any of these procedures regarding Advance Directives?" (with 7 response options); (2) "Where does this agency maintain a copy of its patients' Advance Directives?" (with 4 response options); (3) "What specific actions does this agency take to make sure that patients' Advance Directives are implemented?" (with 4 response options); and (4) "Does this agency have any restrictions on implementing any kinds of Advance Directives? For example, not providing palliative sedation, CPR, or artificial life support services?" If the response to this last item was "yes" respondents were asked to describe the ADs restrictions that were in place at the agency. Responses were collected in a text field in the NHHCS data set. 
Agency Characteristics

The 2007 NHHCS contained information on a number of agency-level variables that we hypothesized to have an impact on ADs. These included agency type (home health only; hospice only; and mixed), ownership (for-profit [FP] vs all others, including nonprofit and government [NP]), whether the facility was a member of a chain (yes/no), number of current patients $(0-50,51-100$, and $>=101)$, and variables describing staff training on cultural differences and communications practices.

Statistical Analysis

Analyses were conducted with the PROC SURVEY procedures in SAS, which take into account the strata, cluster, and weight variables that define the complex sampling approach used in the NHHCS. In addition, the finite population correction was used per NCHS recommendations. Weighted proportions and cross-sectional associations of interest were therefore generated in a manner that renders results generalizeable to the sampling frame of all US HHH agencies on any given day during the survey period of August 2007 to February 2008.

Reporting guidelines were used to determine whether estimates would be presented. The value of the estimate is not reported if it is based on fewer than 30 sample cases. The value of the estimate is reported but should not be assumed to be reliable if it is based on a sample of 30 to 59 cases or if it is based on a sample of 60 or more cases with a relative standard error of greater than $30 \%$. These estimates are noted with an asterisk (“"”). Estimates are reported and considered reliable if they are based on 60 or more sample cases and the relative standard error is less than $30 \% .26$

Results

Table 1 shows characteristics of interest among US HHH agencies, by agency type, in 2007. Nearly 75\% of $\mathrm{HHH}$ agencies provided only home health services, $15.3 \%$ provided only hospice services and about 
$10 \%$ provided both services. A number of differences in agency characteristics potentially related to ADs were noted by agency type, including ownership and patient load. Although more than $90 \%$ of hospiceonly agencies had at least $1 \mathrm{RN}$ on staff who was certified in palliative care, only $32.5 \%$ had an RN on staff who was certified in pain management. Palliative care and pain management certifications were less common in mixed agencies and sufficiently rare in agencies providing only home health services to prevent reporting. Mandatory cultural training was very common (>85\%) for administrative, direct service and volunteer staff in hospiceonly agencies, and this was also provided in the vast majority (>75\%) of mixed agencies. Most HHH agencies provided interpreter services, although mixed agencies provided this service more frequently (87\%) than other agency types. Mixed service agencies also translated patient materials slightly more often (71\%) than hospice only $(64 \%)$ and home health only (61\%) agencies, but these differences were not significant. Similarly, 52\% of mixed service agencies had multilingual staff, a proportion that was larger, but not statistically different than that in other agency types.

Overall, $\mathrm{HHH}$ agency policies on ADs differed little by agency type, and adherence to certain policies approached $100 \%$ (see Table 2). One notable difference was that hospiceonly agencies provided ADs forms to patients more often (92\%) than mixed (84\%) and home health only (78\%) agencies. Although nearly all (99\%) hospice-only agencies educated families about ADs, education on the part of home health only (92.5\%) and mixed agencies (95.2\%) was also high. Relative to hospice only and mixed agencies, nearly twice as many home health only agencies (14.5\%) provided ADs information, forms, and education only if these materials were requested.

Nearly all agencies kept ADs with the patient's records at the agency, but less than half of home health only and mixed agencies kept a copy of ADs with records at patients' homes. Only 56\% of hospice-only agencies kept ADs with the records at patients' homes. More than $90 \%$ of hospice only and mixed agencies implemented ADs by notifying the attending physician, a proportion that was considerably 
higher than the $77 \%$ of home health only agencies that notified attending physicians. Most, but not all, agencies implemented ADs by informing agency staff who provided care to the patient. A majority (91\%) of hospice-only agencies implemented ADs by informing family members, a level that was higher than both mixed (85\%) and home health only (72\%) agencies.

Overall, $7 \%$ of all $\mathrm{HHH}$ agencies had one or more restrictions on implementation of ADs. Cell sizes permitted calculation of an estimate for hospice-only agencies, in which more than $14 \%$ had some kind of restriction on implementation of ADs. Text fields describing agency restrictions on ADs included mentions of restrictions related to offering CPR and the provision of life support, as well as statements about the agency's ethical and religious beliefs, withdrawal of life support, and providing assistance with the taking of one's life.

Among home health only and mixed agencies, NP ownership was associated with higher levels of patient and family education $(P<.0001$ for both home health only and mixed agencies), staff education $(P<.05$, for both home health only and mixed agencies), and a greater likelihood that the agency would inform the attending physician about patients' $A D s(P<.01$ home health only agencies). For profit hospice agencies, however, were more likely to inform physicians about patients' ADs compared to their NP counterparts (Figure 1). Relative to home health only agencies that were part of a chain, those that were not part of a chain were more likely to provide written information to patients ( $98.3 \%$ vs $92.1 \%, P<.05)$, and more likely to provide ADs education to staff $(95.3 \%$ vs $86.3 \%, \mathrm{P}<.05)$. Examination of patient load yielded no pattern suggesting that agency size was systematically associated with relation to ADs policies and procedures (data not shown).

Agencies that had RNs with certification in pain management - the vast majority of which were hospiceonly and mixed agencies-were significantly more likely to store ADs at patient homes $(P=.007)$, and agencies with RNs with certification in pain management or palliative care were slightly more likely to 
engage in a number of AD-related practices that exceeded federal requirements, although these relationships were not statistically significant (Figure 2).

Discussion

This report provides the in-depth, nationally representative data on how $\mathrm{HHH}$ agencies have approached specific aspects of the PSDA. Our data show that although $\mathrm{HHH}$ agencies are nearly universally compliant with minimal federal requirements, they engage to a much more limited degree in AD-related activities beyond what is mandated.

It is well known that provider behavior-including providers of HCBS-is strongly influenced by reimbursement policies, including policies governing, for example, mandatory use, collection, encoding, and transmission of patient outcomes data in the home health setting.29 Indeed, home health providers and hospice programs certified by Medicare and/or Medicaid must comply with the PSDA in order to receive Medicare or Medicaid payments from the federal government.30 It was for this reason that key AD-related items in the NHHCS (see Table 1) were phrased in a manner that closely parallels language in the federal guidance, 30 including items related to distribution of written information on $A D s$, documenting in the patient's medical record whether an $A D$ has been executed and providing staff and community education on ADs. It was therefore not surprising that providers of HHH services in the United States were nearly universally compliant with these policies because compliance is required for agencies to be eligible for federal reimbursement. The small number of agencies that did not report compliance with these policies could be those that are licensed to provide services but not certified by Medicare or Medicaid. Although data on Medicare and Medicaid certification were collected in the NNHS screening process, these variables were not included in the public use data set. Thus, it is not 
possible to determine whether the agencies that did not follow federally mandated ADs policies were agencies that were licensed by not certified.

It should be noted that documentation of ADs in a provider's medical record does not ensure that patients' wishes are honored.31 Indeed, there is abundant evidence supporting the notion that an AD alone is not an effective tool to ensure patient self-determination, the fundamental objective of the PSDA.32 In the home health setting in particular, there are a number of reasons why ADs may not be an effective means of ensuring patient autonomy. For example, patients are often admitted to home health from either an acute care hospital or skilled nursing or rehabilitation facility, which are also PSDA-mandated providers. Patients may therefore believe that AD documents filled out or discussed in one care setting are transferred or otherwise apply to other care settings, even though these records are not always transferred with patients across settings. As in other settings, home health personnel lack incentives and often lack training to ensure that patients have sufficient understanding of their $A D$ options to execute documents that assert their rights. Thus, the nearly universal compliance with certain AD-related policies in the HHH settings should not be confused with the ability of agencies to actually act on wishes that are documented in patients' ADs.

Our data showed that although both $\mathrm{HHH}$ agencies had nearly universal compliance with the requisite features of the PSDA, there was a noticeable drop in the proportion AD-related features that went beyond federally mandated criteria. For example, less than half of home health only and mixed agencies routinely stored ADs documents with the patient's records at the patient's home, and only $56 \%$ of hospice agencies did so. Given that ADs are often implemented or otherwise acted upon by family members and that these records may be all that is available to emergency medical personnel in the event of a crisis, it follows that placement and subsequent access to ADs documents is essential for 
the preferences stipulated in those documents to be implemented. Along the same lines, it should be noted that only $3 \%$ of all agencies had a "special advance directives file at the agency location."

Nearly all agencies reported educating the patient/family about ADs-a requirement under the PSDA, but lower numbers of agencies actually informed family members and next of kin about patients' ADs. ADs education provided by agencies may therefore be general in nature, sufficient to meet PSDA standards, but not necessarily specific to the circumstances or preferences of individual patients and families in a manner that would maximize patient autonomy. Indeed, efforts to provide general education to families about ADs, while important and consistent with the PSDA, is not itself aimed at conveying to family members the specific wishes of the patient's end-of-life wishes. This disconnect makes education per se of limited use in using agency-family communications as a vehicle to ensure that the patient's end-of-life preferences are accurately conveyed and ultimately honored. It has been argued that family-based communication focusing on the goals of care-rather than ADs focusing on specific treatments-is the most critical aspect of ACP at the end of life.33

This report has several limitations. First, the NHHCS is cross-sectional, a design that prevents research aimed at describing longitudinal associations. However, the survey provides nationally representative data on various issues related to ADs in the $\mathrm{HHH}$ settings, and therefore offers important benchmarks for policy makers and researchers with an interest in ADs in these service settings. A second issue to consider is that although survey data are an effective means of assessing information that can be ascertained in a straightforward "yes/no" format (eg, compliance with a certain AD policy or document storage procedure), survey data are less effective at providing an understanding of subtle issues associated with implementation of policies in a real world setting as these subtleties are often qualitative and not easily captured as a discrete data point. For example, our data showed that although more than $92 \%$ of $\mathrm{HH}$ only agencies educated the family and patient about ADs, only $77 \%$ of 
these agencies notified the attending physician and $72 \%$ informed family members about the patient's ADs. Given that provision of health services to seniors is often the result of a complex interplay among the patient, his or her family, and professional care providers, it is useful to understand how agencylevel communications to key players outside the agency might influence the likelihood that patients' ADs will not only reside in an agency's files but will also reside in the minds of key players in the patients' formal and informal care network. However, this type of qualitative information can be challenging to collect in a survey format and was not captured in the NHHCS. Despite the limitation of the data, the NHHCS highlights potential areas for improvement in the way that HCBS providers interact with families and attending physicians in the context of communicating patients' ADs and how organizational characteristics may influence how agencies approach ADs.

It is in this context that it should be noted that on some measures, NP agencies outperform their FP counterparts when it comes to engaging in practices that go beyond federally mandated activities, and in a few instances, agencies that were not part of a chain showed evidence of more engagement with ADs activities relative to those that are part of a chain. These observations are consistent with our previous work on ADs and end-of-life programs which showed that ADs were more common in nursing home residents in NP facilities 34 and that end-of-life programs were more common in nursing homes that were not part of a chain.35 The latter report examined various organizational features that could help explain a higher likelihood that nursing homes would participate in end-of-life programs and found that facilities that were more highly engaged in end-of-life programs had a clustering of programs, staff training, and services that were conductive to these activities. Indeed, our data showing that several "optional" activities related to ADs - passing out forms, storage of documents at home, and informing physicians and family-were all more common at agencies where there was at least 1 RN certified in pain management or palliative care. This lends further evidence to the idea that the manner in which 
end-of-life practices are operationalized at the provider level results from a combination of factors that are driven by reimbursement and availability of staff with specialized training related to end-of-life care.

This report demonstrates that $\mathrm{HHH}$ agencies in the United States have nearly universal compliance with basic requirements set out in the PSDA. Although fewer agencies engage in practices that are beyond what is federally mandated, a majority of agencies-especially NP agencies-have adopted implementation strategies aimed at meeting the goals of the PDSA.

Declaration of Conflicting Interests

The author(s) declared no potential conflicts of interests with respect to the authorship and/or publication of this article.

Funding

The author(s) received no financial support for the research and/or authorship of this article. 
References

1. http://www.geog.ufl.edu/faculty/PPAR_Winter_2009_Golant_FINAL.pdf. Accessed May 17, 2010.

2. http://www.aahsa.org/uploadedFiles/IFAS/Publications_amp;_Products/Itc_choices_final.pdf. Accessed May 17, 2010.

3. Law R. 'Bridging worlds': meeting the emotional needs of dying patients. J Adv Nurs. 2009;65(12):2630-2641.

4. lecovich E, Carmel S, Bachner YG. Where they want to die: correlates of elderly persons' preferences for death site. Soc Work Public Health. 2009;24(6):527-542.

5. Schrader SL, Nelson ML, Eidsness LM. "South Dakota's Dying to Know": a statewide survey about end of life. J Palliat Med. 2009;12(8):695-705.

6. Mitty E, Flores S. There's no place like home. Geriatr Nurs. 2009;30(2):126-129.

7. Wilson DM, Truman CD, Thomas $\mathrm{R}$, et al. The rapidly changing location of death in Canada, 19942004. Soc Sci Med. 2009;68(10):1752-1758.

8. Mehta A, Cohen SR, Carnevale FA, Ezer H, Ducharme F. Strategizing a game plan: family caregivers of palliative patients engaged in the process of pain management. Cancer Nurs. 2010;33(6):461-469.

9. Burns CM, Abernethy AP, Leblanc TW, Currow DC. What is the role of friends when contributing care at the end of life? Findings from an Australian population study. Psychooncology. 2011;20(2):203-212. 
10. Young Y, Inamdar S, Hannan EL. Comparison study on functional outcomes and perceived quality of life between all-inclusive and fee-for-service continuing care retirement communities. J Am Med Dir Assoc. 2010;11(4):257-262.

11. Kamp BJ, Wellman NS, Russell C. Position of the American Dietetic Association, American Society for Nutrition, and Society for Nutrition Education: food and nutrition programs for community-residing older adults. J Nutr Educ Behav. 2010;42(2):72-82.

12. Zidén L, Frändin K, Kreuter M. Home rehabilitation after hip fracture. A randomized controlled study on balance confidence, physical function and everyday activities. Clin Rehabil. 2008;22(12):10191033.

13. Singer PA, Martin DK, Kelner M. Quality end-of-life care: patients' perspectives. JAMA. 1999;281(2):163-168.

14. Kellogg FR, Crain M, Corwin J, Brickner PW. Life-sustaining interventions in frail elderly persons. Talking about choices. Arch Intern Med. 1992;152(11):2317-2320.

15. Terry W, Olson LG, Wilss L, Boulton-Lewis G. Experience of dying: concerns of dying patients and of carers. Intern Med J. 2006;36(6):338-346.

16. Steinhauser KE, Christakis NA, Clipp EC, McNeilly M, Mclntyre L, Tulsky JA. Factors considered important at the end of life by patients, family, physicians and other care providers. JAMA. 2000;284(19):2476-2482.

17. Ben Natan M, Garfinkel D, Shachar I. End-of-life needs as perceived by terminally ill older patients, family and staff. Eur J Oncol Nur. 2010;14(4):299-303. 
18. http://www.jchs.harvard.edu/publications/seniors/lawler_w01-13.pdf. Accessed May 17, 2010.

19. http://www.cdc.gov/nchs/data/nhhcs/NHHCSTrendTable_022310.pdf. Accessed May 17, 2010.

20. http://www.cdc.gov/nchs/data/series/sr_13/sr13_126.pdf. Accessed May 17, 2010.

21. http://www.cdc.gov/nchs/data/series/sr_13/sr13_141.pdf. Accessed May 17, 2010.

22. Omnibus Budget Reconciliation Act of 1990, Pub. L. No. 101-508 § 4206, 4751.

23. Silveira MJ, Kim SY, Langa KM. Advance directives and outcomes of surrogate decision making before death. N Engl J Med. 2010;362(13):1211-1218.

24. Detering KM, Hancock AD, Reade MC, Silvester W. The impact of advance care planning on end of life care in elderly patients: randomised controlled trial. BMJ. 2010;340:c1345; doi: 10.1136/bmj.c1345.

25. http://www.cdc.gov/nchs/nhhcs/nhhcs_questionnaires.htm. Accessed April 21, 2010.

26. http://www.cdc.gov/nchs/data/series/sr_01/sr01_053.pdf. Accessed October 5, 2010.

27. http://www.cdc.gov/nchs/data/nhhcsd/NHHCS_NHHAS_web_documentation.pdf. Accessed April 21, 2010.

28. http://www.cdc.gov/nchs/data/nhhcsd/Agency_NHHCSO7Questionnaire.pdf. Accessed April 22, 2010.

29. https://www.cms.gov/OASIS/03_Regulations.asp\#TopOfPage. Accessed October 7, 2010.

30. http://www.cms.gov/manuals/downloads/som107c02.pdf. Accessed October 7, 2010. 
31. Fagerlin A, Schneider CE. Enough: the failure of the living will. Hastings Cent Rep. 2004;34(2):30-

42.

32. Kirschner KL. When written advance directives are not enough. Clin Geriatr Med. 2005;21(1):193-

209.

33. Tulsky JA. Beyond advance directives: importance of communication skills at the end of life. JAMA. 2005;294(3):359-365.

34. Resnick HE, Schuur JD, Heineman J, Stone R, Weissman JS. Advance directives in nursing home residents aged >=65 years: United States 2004. Am J Hosp Palliat Care. December/January 2009;25(6):476-482.

35. Resnick HE, Foster GL, Hickman SE. Nursing home participation in end-of-life programs: United States, 2004. Am J Hosp Palliat Care. 2009;26(5):354-360. 
Table 1. Selected Characteristics of Home Health and Hospice Agencies, by Agency Type, United States,

$2007 a$

\begin{tabular}{|c|c|c|c|c|c|}
\hline & $\begin{array}{c}\text { Total \% } \\
\text { (Weighted } n \text { ) }\end{array}$ & $\begin{array}{l}\text { Home Health Only } \\
\% \text { (Weighted } n)\end{array}$ & $\begin{array}{l}\text { Hospice Only \% } \\
\text { (Weighted n) }\end{array}$ & $\begin{array}{c}\text { Mixed \% } \\
\text { (Weighted n) }\end{array}$ & p \\
\hline Total & $100.0(14469)$ & $74.8(10816)$ & $15.3(2218)$ & $9.9(1435)$ & \\
\hline Member of chain & $30.0(4343)$ & $32.2(3479)$ & $27.6(612)$ & $17.6(252)$ & .10 \\
\hline For-profit owmership & $65.0(9406)$ & $75.5(8165)$ & $39.4(873)$ & $25.6(368)$ & $<, \infty 001$ \\
\hline \multicolumn{6}{|l|}{ Current home health patients } \\
\hline 0.49 & $37.0(4531)$ & $37.3(4031)$ & N/A & $34.8(500)$ & .10 \\
\hline 50.99 & 27.7 (3398) & $29.0(3134)$ & N/A & $18.4(264)$ & \\
\hline $100+$ & $35.3(4322)$ & $33.8(3651)$ & N/A & $46.8(671)$ & \\
\hline \multicolumn{6}{|l|}{ Current hospice patients } \\
\hline 0.49 & $66.6(2322)$ & N/A & $54.7(1144)$ & $84.3(1178)$ & $<.0001$ \\
\hline 50.99 & $16.1(562)^{\prime}$ & N/A & $225(471)$ & $6.5(91)$ & \\
\hline $100+$ & $17.3(605)$ & N/A & $22.8(477)$ & - & \\
\hline RN palliative care certification & $39.1(2183)$ & - & $91.1(1254)$ & $69.6(578)$ & $<.0001$ \\
\hline RN pain management certification & $22.4(1178)$ & - & $325^{6}(387)$ & $28.0^{\circ}(206)$ & .21 \\
\hline \multicolumn{6}{|l|}{ Mandatory cultural training } \\
\hline All administrative staff & $70.7(9073)$ & $66.7(6287)$ & $86.2(1767)$ & $75.9(1019)$ & $<.01$ \\
\hline All direct service providers & $76.1(9763)$ & $73.0(6878)$ & $88.0(1803)$ & $79.6(1082)$ & .03 \\
\hline All volunteers & $28.5(3660)$ & $9.4^{6}(885)$ & $85.4(1750)$ & $75.4(1025)$ & $<.0001$ \\
\hline \multicolumn{6}{|l|}{ Communications practices } \\
\hline Interpreter services & $73.7(10534)$ & $70.4(7560)$ & $81.0(1721)$ & $87.3(1253)$ & .01 \\
\hline Translation of patient materials & $62.5(8929)$ & $60.9(6536)$ & $64.3(1366)$ & $71.6(1027)$ & .34 \\
\hline Multi-lingual stoff & $49.3(7051)$ & $49.2(5285)$ & 47.6 (1011) & $526(755)$ & .86 \\
\hline
\end{tabular}

"Data are presented as $\$$ (weighted $n$ ) using SAS SURVEYFREQ. Some caugories may not add to 100.0 due to rounding or missing data. $P$ values are for Chisquare tests of dfferences in proportions across groups.

"Estimates should be interpreted with caution; $[-]$ ind kates small cell sice that violated reporting guidelines. 
Table 2. Advance Directive Policy, Storage, and Implementation, by Agency Type, 2007 National Home and Hospice Care Survey

\begin{tabular}{|c|c|c|c|c|c|}
\hline & $\begin{array}{c}\text { All \% } \\
\text { (weighted } n \text { ) }\end{array}$ & $\begin{array}{l}\text { Home health Only \% } \\
\text { (Weighted n) }\end{array}$ & $\begin{array}{l}\text { Hospice only \% } \\
\text { (meighted n) }\end{array}$ & $\begin{array}{c}\text { Mixed \% } \\
\text { (Weighted n) }\end{array}$ & $p$ \\
\hline & $100.0(14469)$ & $74.8(10816)$ & $15.3(2218)$ & $9.9(1435)$ & \\
\hline \multicolumn{6}{|l|}{ Aovance directives policies } \\
\hline $\begin{array}{l}\text { On admission, assess whether patient has any } \\
\text { advance directives }\end{array}$ & $96.8(13889)$ & $96.1(10374)$ & $99.4(2114)$ & $97.6(1401)$ & .24 \\
\hline $\begin{array}{l}\text { On admission, provide mitten information } \\
\text { about advance directives }\end{array}$ & $96.2(13806)$ & $96.3(10398)$ & $94,9(2017)$ & $96.9(1391)$ & .84 \\
\hline $\begin{array}{l}\text { On admission, provide advance directive form (s) } \\
\text { to patient }\end{array}$ & $80.9(11609)$ & $78.3(8447)$ & $92.0(1955)$ & $84.1(1207)$ & .03 \\
\hline Educate patient/emily about advance directives & $93.7(13449)$ & $925(9979)$ & $99.0(2104)$ & $95.2(1366)$ & .02 \\
\hline Educate agency staff about advance directives & $93.5(13422)$ & $924(9976)$ & $96.6(2053)$ & $97.1(1393)$ & .16 \\
\hline $\begin{array}{l}\text { Only if requested, provide information, forms, } \\
\text { education }\end{array}$ & $12.8(1841)$ & $145^{\circ}(1563)$ & $8.0^{\circ}(170)$ & $7.5^{\circ}(108)$ & .02 \\
\hline \multicolumn{6}{|l|}{ Aorvance directive storage } \\
\hline With patient's records at agency & $94.4(13462)$ & $93.8(10041)$ & $98.4(2092)$ & $92.6(1329)$ & .11 \\
\hline With patient's reconds at patient's residence & $48.8(6968)$ & $47.6(5092)$ & $56.1(1192)$ & $47.7(684)$ & .44 \\
\hline $\begin{array}{l}\text { In a special advance directives file at agency } \\
\text { location }\end{array}$ & $3.3^{6}(467)$ & - & - & - & \\
\hline \multicolumn{6}{|l|}{ Advance directive implementation } \\
\hline Nocify attending physician & $80.8(11593)$ & $77.1(8322)$ & $92.2(1960)$ & $91.6(1311)$ & $<.0001$ \\
\hline Inform agency staff providing care to patient & $96.6(13868)$ & $96.1(10378)$ & $97.4(2070)$ & $99.2(1420)$ & .20 \\
\hline Inform family memberinext of kin & 76.5 (10972) & $725(7823)$ & $90.8(1930)$ & $85.1(1219)$ & $<.0001$ \\
\hline $\begin{array}{l}\text { Does agency have any restrictions on imple- } \\
\text { mentation of } A D \text { ? }\end{array}$ & $7.0(999)$ & - & $14.4(305)$ & - & $n / 2$ \\
\hline
\end{tabular}


Figure 1. Home health and hospice agency policies related to advance directive in home health and hospice agencies, by ownership, United States, 2007.

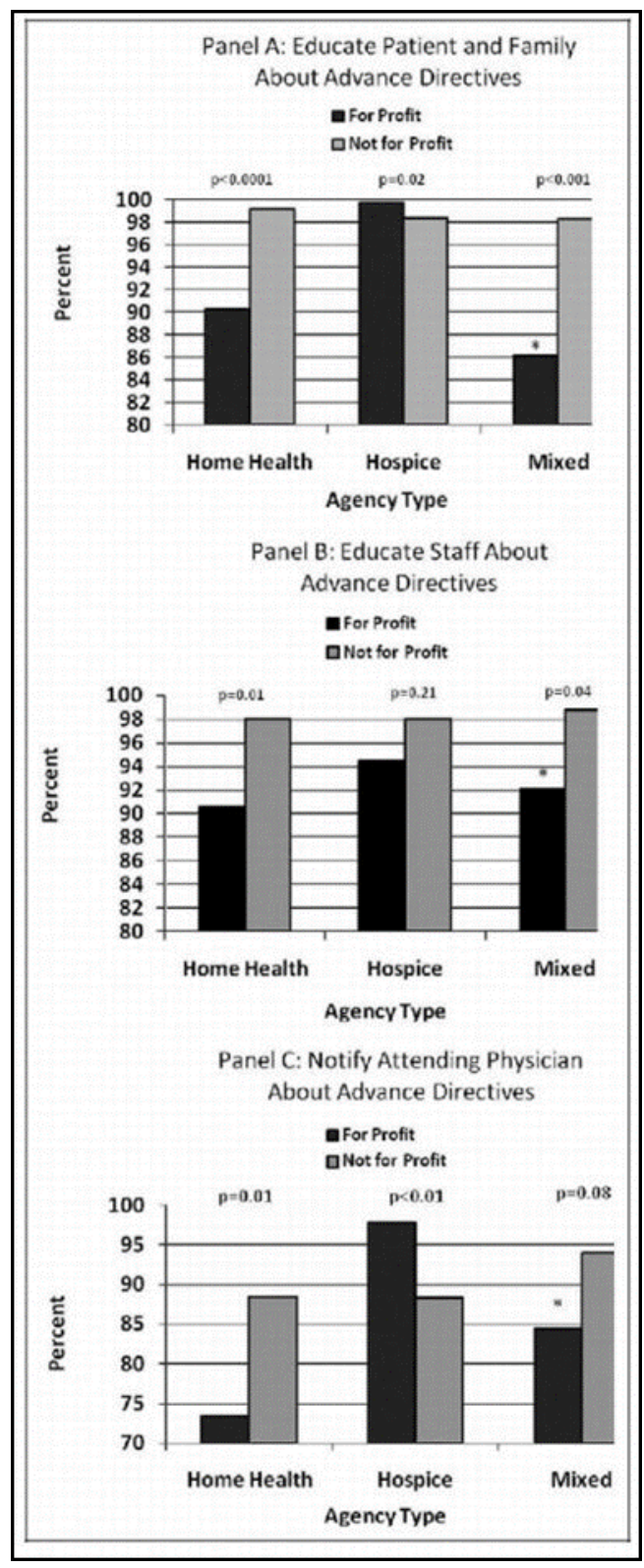


Figure 2. Selected practices associated with advance directives among home health and hospice agencies, by RN certification in pain management and palliative care, United States, 2007.

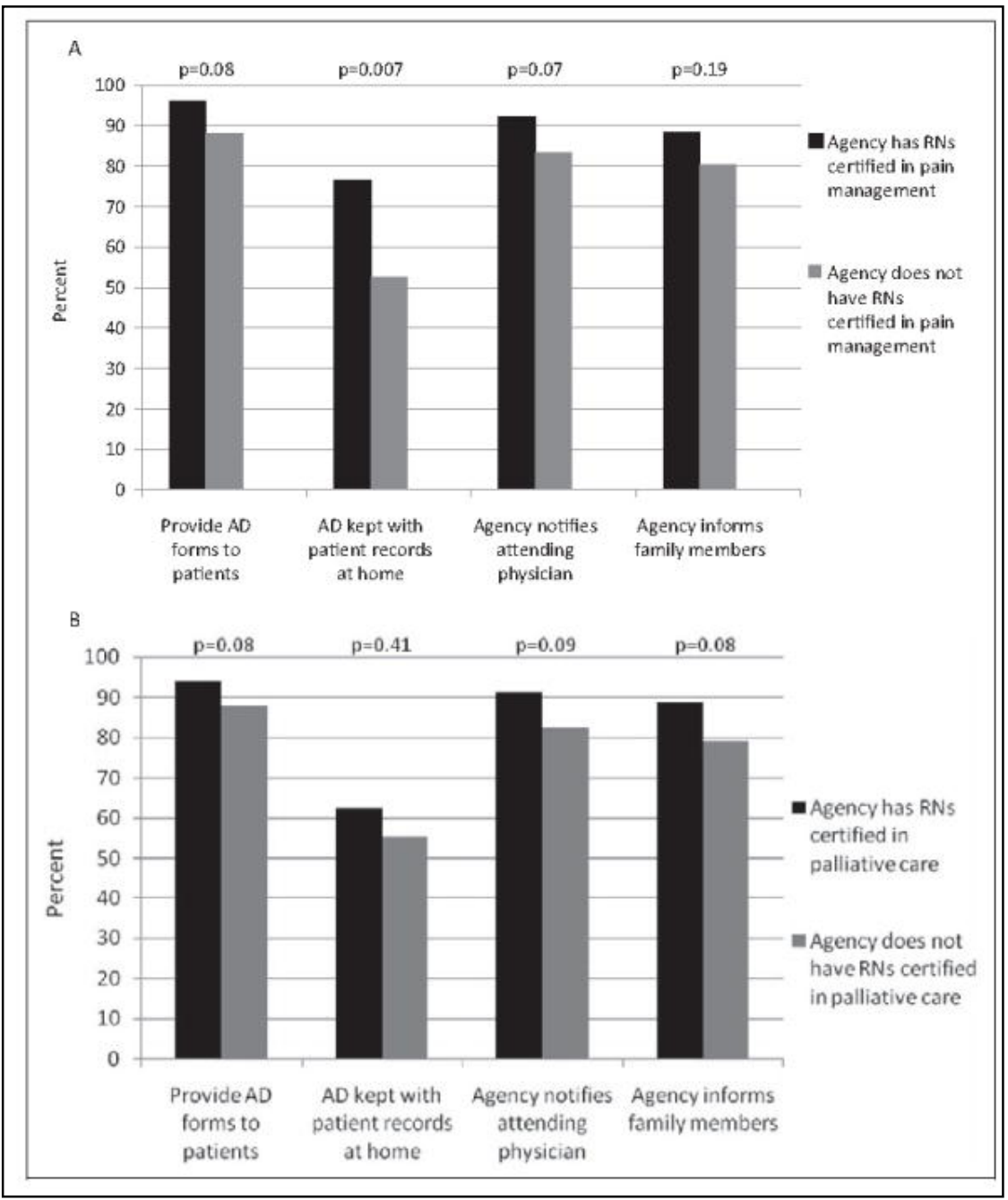

